\title{
Numerical Analysis of Carbon Fiber Reinforced Plastic (CFRP) Shear Walls and Steel Strips under Cyclic Loads Using Finite Element Method
}

\author{
Nahid Askarizadeh \\ Department of Civil Engineering \\ Faculty of Engineering \\ Bandar Abbas Branch \\ Islamic Azad University \\ Bandar Abbas, Iran
}

\author{
Mohammad Reza Mohammadizadeh \\ Department of Civil Engineering \\ Faculty of Engineering \\ Hormozgan University \\ Bandar Abbas, Iran
}

\begin{abstract}
Reinforced concrete shear walls are the main elements of resistance against lateral loads in reinforced concrete structures. These walls should not only provide sufficient resistance but also provide sufficient ductility in order to avoid brittle fracture, particularly under strong seismic loads. However, many reinforced concrete shear walls need to be stabilized and reinforced due to various reasons such as changes in requirements of seismic regulations, weaknesses in design and execution, passage of time, damaging environmental factors, patch of rebar in plastic hinges and in some cases failures and weaknesses caused by previous earthquakes or explosion loads. Recently, Fiber Reinforced Polymer (FRP) components have been extensively and successfully used in seismic improvement. This study reinforces FRP reinforced concrete shear walls and steel strips. CFRP and steel strips are evaluated by different yield and ultimate strength. Numerical and experimental studies are done on walls with scale $1 / 2$. These walls are exposed to cyclic loading. Hysteresis curves of force, drift and strain of FRP strips are reviewed in order to compare results of numerical work and laboratory results. Both numerical and laboratory results show that CFRP and steel strips increase resistance, capacity and ductility of the structure.
\end{abstract}

Keywords-numerical analysis; shear wall; FRP; lateral load; ABAQUS

\section{INTRODUCTION}

Polymer coatings used to improve concrete structures were first developed in 1980 in Europe and Japan. In Europe, FRP systems were used as an alternative to steel plates. Connection of steel plates to tensile part of concrete members by epoxy resins is a common durable method to enhance bending strength of these members. Steel plates are corroded and their corrosion leads to the collapse of steel plates with concrete. Moreover, they are difficult to install, because they are installed by heavy machinery. Thus, scientists tended to replace steel coatings by FRP materials. With almost $20 \%$ of the weight of steel coatings, FRP is approximately 8 to 10 times more resistant than steel. One of the problems with system structural calculations is the difficulty of computer modeling in the form of finite element. Moreover, variation in effective parameters on behavior of these structures challenges laboratory methods due to high cost and time. Numerical methods also require a correct understanding of non-linear behavior of reinforced concrete and FRP [1]. This study develops suitable structural models and models non-linear behavior of concrete, reinforcement and FRP.

\section{PROBLEM DESCRIPTION}

\section{A. Concrete Damage Plasticity}

The most important step in numerical modeling of reinforced concrete structures is the determination of concrete's nonlinear behavior. In the finite element software ABAQUS, nonlinear behavior of brittle materials can be defined through three models: 1) smeared cracking, 2) brittle cracking and 3) concrete damage plasticity [2]. Concrete damage model is the only model which can be used in both static and dynamic analysis. In this model, it is assumed that tensile cracking and compressive crushing are two main aspects of concrete failure mechanism. In modeling brittle material cracking under cyclic loading (alternating tension and compression), stiffness recovery is allowed during reciprocating loads [3]. In plastic damage model, elimination of elements and cracking are not allowed during analysis due to the lack of failure criterion, however, this model is able to predict location and direction of cracks.

\section{B. Interpretation of Moment - Curvature Curve for Reinforced Concrete Shear Wall Section}

Unlike the simplicity in design and construction of reinforced concrete shear walls, the real response of these elements is rather complex. Overall behavior of walls is influenced by bending, shear and axial responses. Wall sections are against compressive axial forces caused by gravity loads and their own weight. Axial pressure acting on the wall is estimated at $20 \%$ of product of concrete compressive strength, $\mathrm{f}_{\mathrm{c}}^{\prime}$, in $\mathrm{A}_{\mathrm{g}}$ (gross concrete cross section) [4]. Authors in [4] described the moment-curvature relationship in walls of highrise buildings against a unidirectional load. When bending moment is applied on the wall section, initial response of the wall is linear elastic with initial flexural stiffness. Cracking 
occurs when moment exceeds initial elasticity and flexural stiffness is reduced by growth of the first crack and start of additional cracks. Slope of this phase results from approximately parallel response of flexural stiffness of the cracked and deformed section. Further increase in the applied moment leads to the weakening of steel and the section's capacity. It is thus considered essential to use non-linear analysis and theories of plasticity to simulate behavior of reinforced concrete shear wall.

Uniaxial stress-strain relationship of concrete under pressure and tension is an important parameter in importing concrete damage plasticity model to the software. To do this, the Hognestad curve is used. Equations (1) and (2) are used to import compressive stress of concrete versus compressive strain to the software. In these equations, $\varepsilon_{0}$ is the corresponding strain to maximum stress. For specimens of which $\varepsilon_{0}$ is unknown, this study uses the value 0.002 , which is a rational value for conventional concretes [5]. In (2), $f_{\mathrm{c}}^{\prime \prime}$ is maximum stress in concrete element. The $\mathrm{k}_{\mathrm{s}}$ factor can be considered as portrayed in Table I [5] for concretes with cylindrical compressive strength. Descending branch of the modified Hognestad curve is linear which extends from $\varepsilon_{0}, \mathrm{f}_{\mathrm{c}}$ to $\varepsilon_{u}, 0.85 \mathrm{f}_{\mathrm{c}}^{\prime \prime} . \varepsilon_{u}$ corresponds to ultimate corresponding strain to compressive failure of concrete, which has been reported from 0.003 to higher than 0.005 . This study considers 0.0038 .

$$
\begin{aligned}
& f_{c}=f_{c}^{\prime \prime}\left[\frac{2 \varepsilon_{c}}{\varepsilon_{0}}-\left(\frac{\varepsilon_{c}}{\varepsilon_{0}}\right)^{2}\right] \\
& f_{c}^{\prime \prime}=k_{s} f_{c}^{\prime}
\end{aligned}
$$

TABLE I. $\quad \mathrm{k}_{\mathrm{S}}$ VALUES IN HOGNESTAD CURVE

\begin{tabular}{|c|c|c|c|c|c|}
\hline $\mathrm{f}_{\mathrm{c}}^{\prime}(\mathrm{MPA})$ & 15 & 20 & 25 & 30 & $>35$ \\
\hline $\mathrm{k}_{\mathrm{s}}$ & 1 & 0.97 & 0.95 & 0.93 & 0.92 \\
\hline
\end{tabular}

\section{Stress-Strain Under Tension by Using ABAQUS- Suggested Equation}

Concrete alone cannot tolerate tensile stresses and its tensile strength is low (7\%-11\% of compressive strength). Steel rebar is usually used to compensate these problems. Concrete tensile response begins with cracking and its expansion. Thus, concrete behavior cannot be evaluated by considering tensile strain. Instead, the crack should be evaluated. The concrete response under pressure is linear until it reaches its tensile strength which is associated with very fine cracks. The increase in loading decreases resistance and expands cracks to fracture under ultimate strain [6-7]. A straight line is usually used for softening part of tensile curve. Moreover, tensile strength and ultimate strain are calculated by following equations [8-10]:

$$
\begin{aligned}
& f_{t}^{\prime}=0.33 \sqrt{f_{c}^{\prime}} \\
& \varepsilon^{*}=0.001
\end{aligned}
$$

In periodic loading, stiffness decreases and cracks after each cycle emerge. Unlike compressive cracks, these cracks are completely obvious and open [6]. The curves presented for the static scenario are in fact pushover curves of maximum stresses under periodic loading.

\section{Damage Parameter}

The slope of unloading curve is lower than the slope of the elastic curve in the softening part, which indicates damage. The reduced initial stiffness is shown by $d_{t}$ and $d_{c}$ (stiffness decline under tension, and $d_{c}$ stiffness decline under pressure respectively). It is assumed that these two variables are functions of plastic strain, temperature and other field variables [3].

$$
\begin{array}{ll}
d_{t}=d_{t}\left(\varepsilon_{t}^{p l}, \theta, f_{i}\right) & 0 \leq d_{t} \leq 1 \\
d_{c}=d_{c}\left(\varepsilon_{c}^{p l}, \theta, f_{i}\right) & 0 \leq d_{c} \leq 1
\end{array}
$$

where, $\varepsilon_{\mathrm{c}}^{p l} \boldsymbol{q}_{\mathrm{q}}^{p l}$ and $\varepsilon_{t}^{p l} s_{\tau}^{F^{l}}$ are corresponding plastic strains under pressure and tension, $\theta^{\theta}$ is the temperature, and $\mathrm{f}_{\mathrm{i}} f_{\mathrm{i}}$ is the field variable. In fact, concrete damage is determined by $d_{t}$ and $\mathrm{d}_{\mathrm{c}}$ in uniaxial stress-strain curves. These damage variables are expressed as follows:

$$
E=\left(1-d_{t, c}\right) E_{0}
$$

where $\boldsymbol{E}_{\mathrm{E}}$ is the damaged module of elasticity, $\boldsymbol{E}_{\mathrm{n}} \mathrm{E}_{0}$ is undamaged module of elasticity. It is important to select properties of damage, because excessive damage values have unsuitable effect on convergence rate.

\section{E. Behavior of Reinforcements}

There are many stress-strain models in finite element software. This study uses a bilinear elastoplastic model for reinforcement. In ABAQUS, longitudinal and transverse reinforcements are modeled by two-node truss element T3D2 which is only able to tolerate axial force and acts separately from concrete.

\section{F. Stiffness Recovery in ABAQUS}

Stiffness recovery is an important discussion in the mechanical response of concrete in periodic loading. In ABAQUS, the user can directly import the stiffness recovery factors, $w_{t}$ and $w_{c}$. In the majority of quasi-brittle materials such as concrete reflect improvement of compressive stiffness resulting from closure of cracks when loading shifts from tension to compression. On the other hand, tensile stiffness is not recovered by this shift after formation of microcracks under concrete crushing. This behavior which is related to $\mathrm{w}_{\mathrm{t}}=0$ and $\mathrm{w}_{\mathrm{c}}=1$ is default in ABAQUS. 


\section{SPECIMENS}

\section{A. Reinforced concrete shear walls specimens}

Group A: Five specimens of CFRP reinforced concrete 1

shear walls tested by authors in [11] at scale of $2 \frac{1}{2}$ are modeled in different arrangements of CFRP in ABAQUS. All specimens are $1000 \mathrm{~mm}$ in length, $100 \mathrm{~mm}$ in width and $1500 \mathrm{~mm}$ in height. All specimens are exposed to cyclic loading with drift control. Group B: Three specimens of CFRP reinforced concrete shear walls tested in [12] are modeled in different arrangements of CFRP in ABAQUS. All specimens are 1200 $\mathrm{mm}$ in length, $80 \mathrm{~mm}$ in width and $1045 \mathrm{~mm}$ in height. All specimens are exposed to cyclic loading with drift control and $48 \mathrm{kN}$ compressive axial force and two axial forces, one compressive and the other tensile, in a distance which forms couple on top of the wall, as shown in (8) and (9).

$$
\begin{aligned}
& F_{A}=24+1.115 F_{C} \\
& E=\left(1-d_{t, c}\right) E_{0}
\end{aligned}
$$

Group C: Four specimens of steel strip reinforced concrete shear walls tested in [13] at scale of $1 / 2$ are modeled in different arrangements of steel strips in ABAQUS. All specimens are $1000 \mathrm{~mm}$ in length, $100 \mathrm{~mm}$ in width and $1500 \mathrm{~mm}$ in height. All specimens are exposed to cyclic loading with drift control

\section{B. Specifications of materials}

Group A: specimen 1 which is unreinforced is selected as reference specimen. Four other specimens are determined (Specimen 2, Specimen 3, Specimen 4 and Specimen 5). All four reinforced specimens have a layer reinforced by CFRP strips [11]. Group B: CW which is unreinforced is selected as reference specimen. Two other specimens are determined (RW1 and RW2). All two reinforced specimens have a layer reinforced by CFRP strips [2]. Group C: specimen 1 which is unreinforced is selected as reference. Three other specimens are determined (Specimen 2, Specimen 3 and Specimen 4). All three reinforced specimens have a layer reinforced by steel strips [13]. Table II shows 28-day resistance of concrete in all specimens. Table III shows yield and ultimate strength of rebar used in this experiment. Values of shear modulus $(\mathrm{G})$ are given in Tables IV and V.

\section{RESULTS}

\section{A. $\quad$ Group A}

Figure 1 shows the force-drift hysteresis curve of numerical analysis for Group A specimens under cyclic load [11]. Figure 3 shows the strain-force hysteresis curve of CFRP materials in numerical analysis for Group A Specimens under cyclic load. Table VI lists the experimental results and compares them to numerical results related to maximum strain. As shown, the numerical analysis is consistent with the experimental results.

TABLE II. SPECIFICATIONS OF SPECIMENS

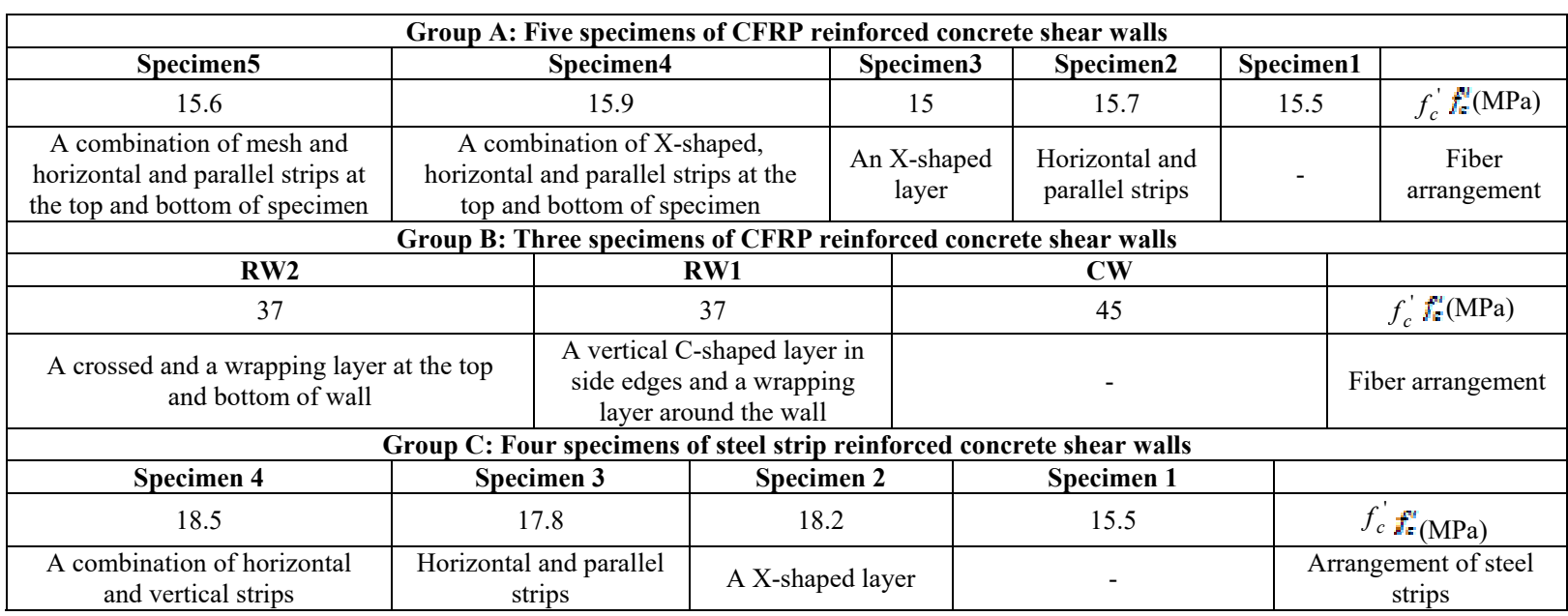

TABLE III. SPECIFICATIONS OF REINFORCEMENTS

\begin{tabular}{|c|c|c|}
\hline \multicolumn{3}{|c|}{ Group A: CFRP reinforced concrete shear walls } \\
\hline Ultimate strength (MPa) & Yield strength (MPa) & Reinforcement diameter (mm) \\
\hline 420 & 325 & 6 \\
\hline 522 & 430 & 10 \\
\hline 515 & 428 & 12 \\
\hline 520 & 425 & 16 \\
\hline \multicolumn{1}{|c|}{ Group B: CFRP reinforced concrete shear walls } \\
\hline Ultimate strength (MPa) & Yield strength (MPa) & Reinforcement diameter (mm) \\
\hline 550 & 650 & 10 \\
\hline 720 & 620 & 6 \\
\hline
\end{tabular}




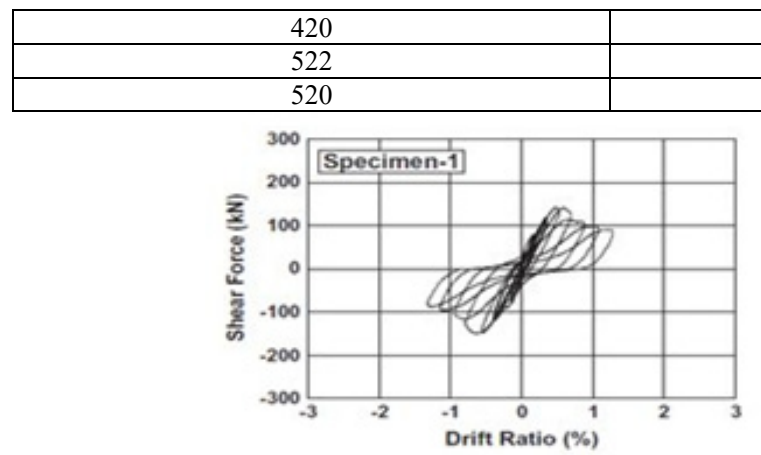

\begin{tabular}{|c|c|}
\hline 325 & 6 \\
\hline 430 & 10 \\
\hline 425 & 16 \\
\hline
\end{tabular}
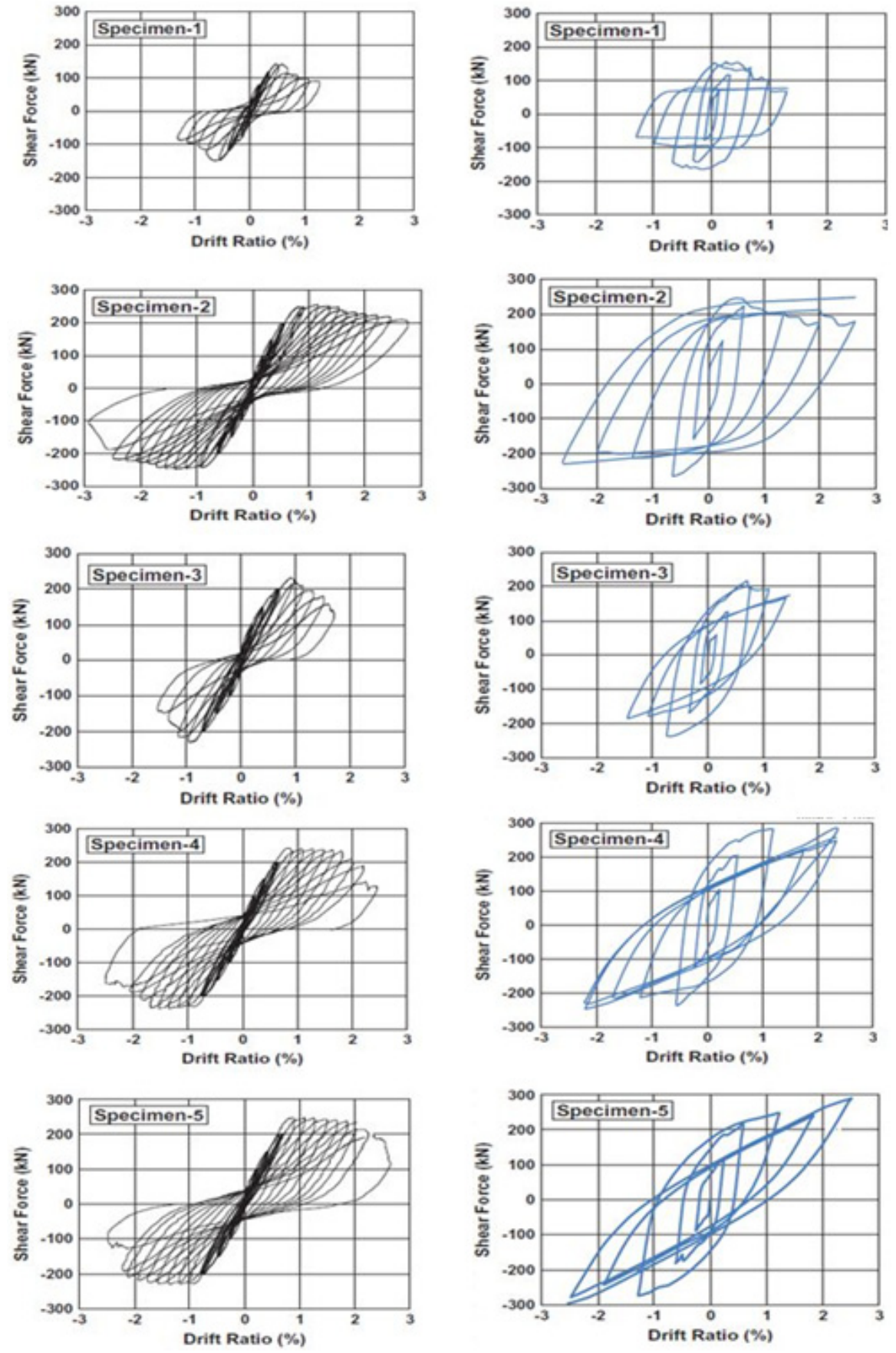

Fig. 1. Force-drift hysteresis curve under cyclic load, Group A, Specimens 1-5 a) experimental b) numerical

TABLE IV. SPECIFICATIONS OF CFRP

\begin{tabular}{|c|c|c|c|c|}
\hline \multicolumn{5}{|c|}{ Group A: CFRP reinforced concrete shear walls } \\
\hline Ultimate strain (\%) & Ultimate tensile stress (MPa) & Modulus of elasticity (MPa) & Thickness (mm) & 0.12 \\
\hline 1.7 & 4100 & 231000 & CFRP \\
\hline \multicolumn{7}{|c|}{ Group B: CFRP reinforced concrete shear walls } \\
\hline Ultimate strain (\%) & Ultimate tensile stress (MPa) & Modulus of elasticity (MPa) & Thickness (mm) & Fiber \\
\hline 1.6 & 3790 & 230 & 0.175 & CFRP \\
\hline
\end{tabular}




\begin{tabular}{|c|c|c|}
\hline \multicolumn{3}{|c|}{ Group C: Steel strip reinforced concrete shear walls } \\
\hline Ultimate strength (MPa) & Yield strength (MPa) & Thickness (mm) Steel strips \\
\hline 470 & 340 & 2.5 \\
\hline
\end{tabular}

TABLE V. INPUT PARAMETERS FOR MODELING FIBERS IN ABAQUS

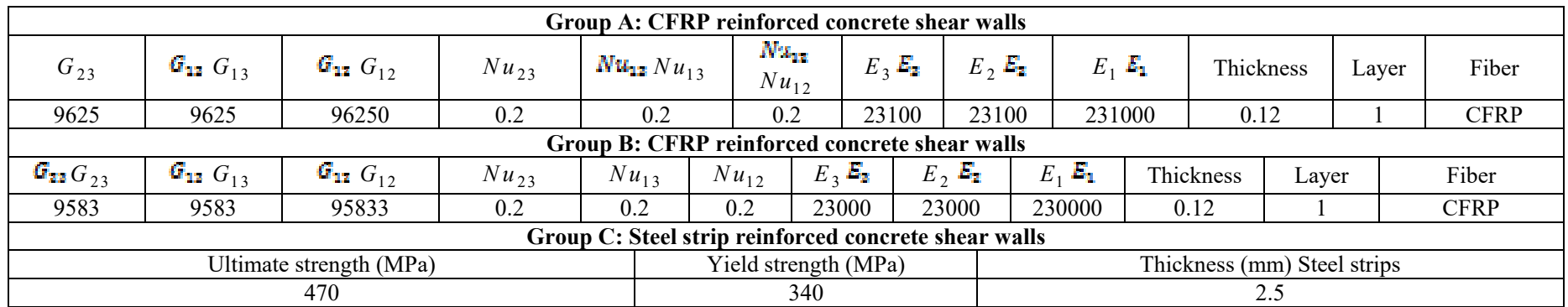
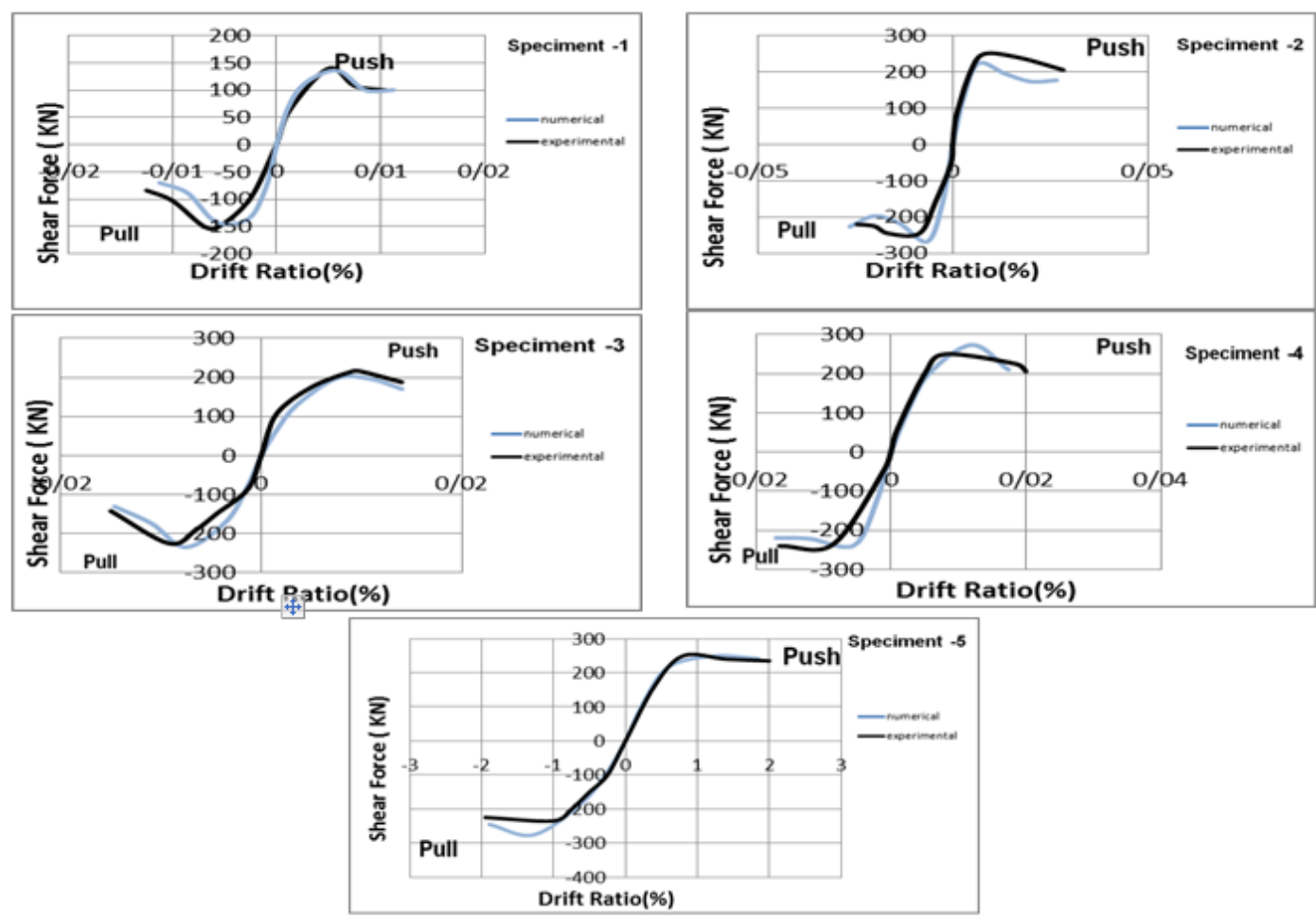

Fig. 2. Push comparison of hysteresis curves of experimental results and numerical analysis (Group A)

TABLE VI. GROUP A: COMPARISON OF MAXIMUM FORCE

\begin{tabular}{|c|c|c|c|c|c|c|}
\hline \multirow{2}{*}{ Specimen } & \multicolumn{2}{|c|}{ Exp } & \multicolumn{2}{c|}{ Num } & \multicolumn{2}{c|}{ Num/ Exp } \\
\cline { 2 - 7 } & $\begin{array}{c}\text { Push } \\
\text { (KN) }\end{array}$ & $\begin{array}{c}\text { Pull } \\
\text { (KN) }\end{array}$ & $\begin{array}{c}\text { Push } \\
\text { (KN) }\end{array}$ & $\begin{array}{c}\text { Pull } \\
\text { (KN) }\end{array}$ & $\begin{array}{c}\text { Push } \\
\text { (KN) }\end{array}$ & $\begin{array}{c}\text { Pull } \\
(\text { KN) }\end{array}$ \\
\hline Specimen1 & 140 & 151.33 & 136.072 & 149.55 & 0.97 & 0.99 \\
\hline Specimen2 & 250 & 254.72 & 225.62 & 267.57 & 0.91 & 1.05 \\
\hline Specimen3 & 215 & 230.22 & 204.55 & 234.63 & 0.95 & 1.02 \\
\hline Specimen4 & 260 & 238 & 273.69 & 239 & 1.05 & 1 \\
\hline Specimen5 & 250 & 245 & 248.5 & 272.3 & 0.99 & 1.11 \\
\hline
\end{tabular}

TABLE VII. GROUP A: MAXIMUM CFRP STRAIN

\begin{tabular}{|c|c|c|c|}
\hline Specimen & Num & Exp & Num/Exp \\
\hline Specimen1 & - & - & - \\
\hline Specimen2 & 0.0073 & 0.0075 & 0.97 \\
\hline Specimen3 & 0.0085 & 0.0095 & 0.89 \\
\hline Specimen4 & 0.0085 & 0.0088 & 0.97 \\
\hline Specimen5 & 0.008 & 0.0083 & 0.96 \\
\hline
\end{tabular}

\section{B. Group B}

Figure 4 shows the force-drift hysteresis curve for Group B: CW, RW1 and RW2 under cyclic load [12] (Table VII). Figure 5 compares push of force-drift hysteresis curves of specimens under cyclic load resulting from experimental numerical analysis. Table VIII lists experimental results and compares them to numerical analysis related to maximum forced obtained in reciprocating cycles. As shown, the numerical analysis for Group B specimens is consistent with the experimental results. Figure 4 shows the strain-force hysteresis curve of CFRP materials in numerical analysis for RW1 and RW2 under cyclic load. Table IX compares the experimental and the numerical results which are shown to be consistent. 

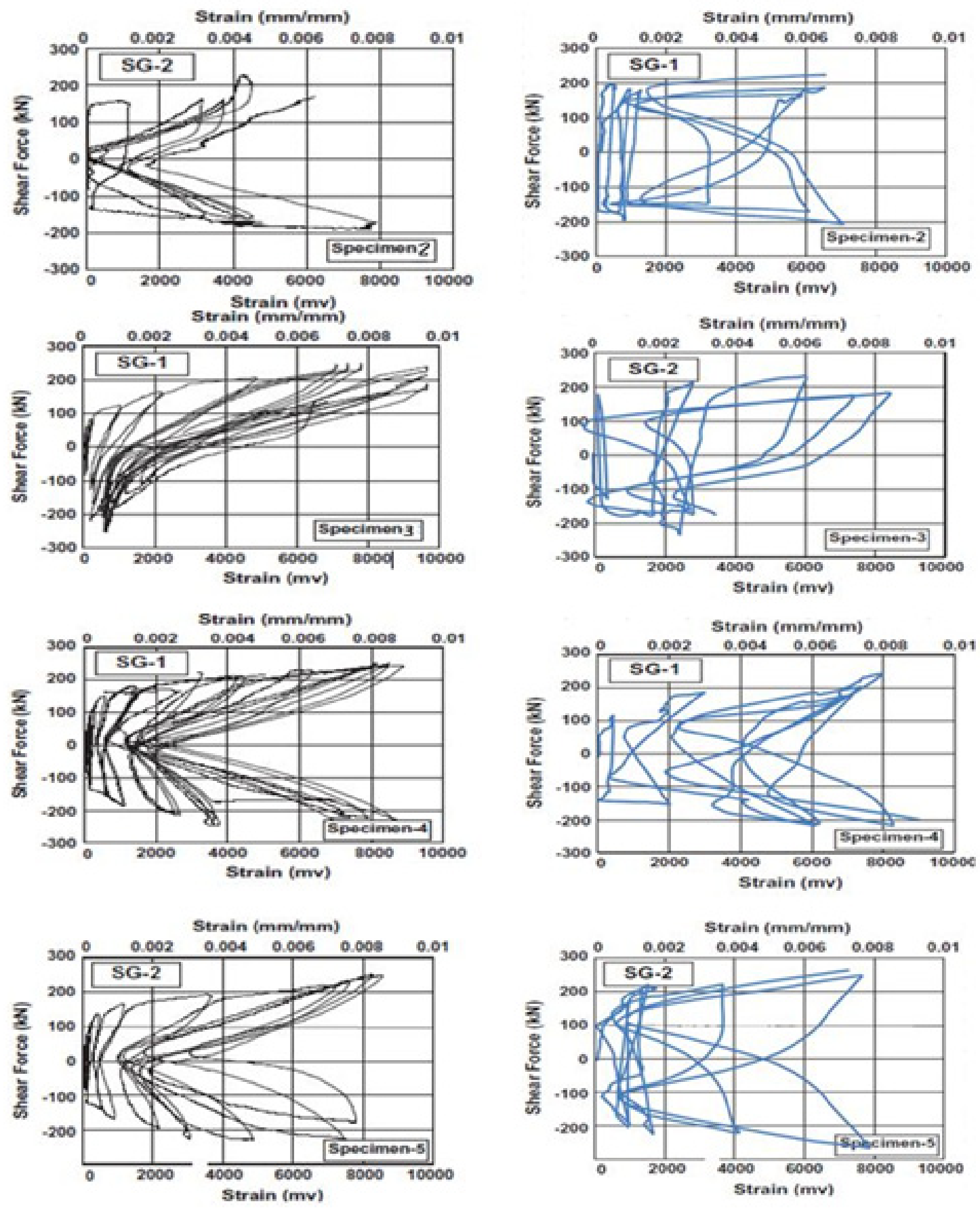

Fig. 3. Strain-force curve of CFRP in Group A, Spesimens 1-5 a) experimental b) numerical

TABLE VIII. GROUP B: COMPARISON OF MAXIMUM FORCE

\begin{tabular}{|c|c|c|c|c|c|c|}
\hline \multirow{2}{*}{ Specimen } & \multicolumn{2}{|c|}{ Exp } & \multicolumn{2}{c|}{ Num } & \multicolumn{2}{c|}{ Num/ Exp } \\
\cline { 2 - 7 } & Push (KN) & Pull (KN) & Push (KN) & Pull (KN) & Push (KN) & Pull (KN) \\
\hline CW & 60 & 60 & 62.53 & 64.52 & 1.04 & 1.075 \\
\hline RW1 & 110 & 110 & 117.53 & 111.63 & 1.06 & 1.01 \\
\hline RW2 & 94 & 90 & 107.82 & 100.33 & 1.14 & 1.11 \\
\hline
\end{tabular}

TABLE IX. GROUP B: MAXIMUM CFRP STRAIN

\begin{tabular}{|c|c|c|c|}
\hline Specimen & Num & Exp & Num/Exp \\
\hline RW1 & 5300 & 5100 & 1.04 \\
\hline RW2 & 4000 & 4300 & 0.93 \\
\hline
\end{tabular}



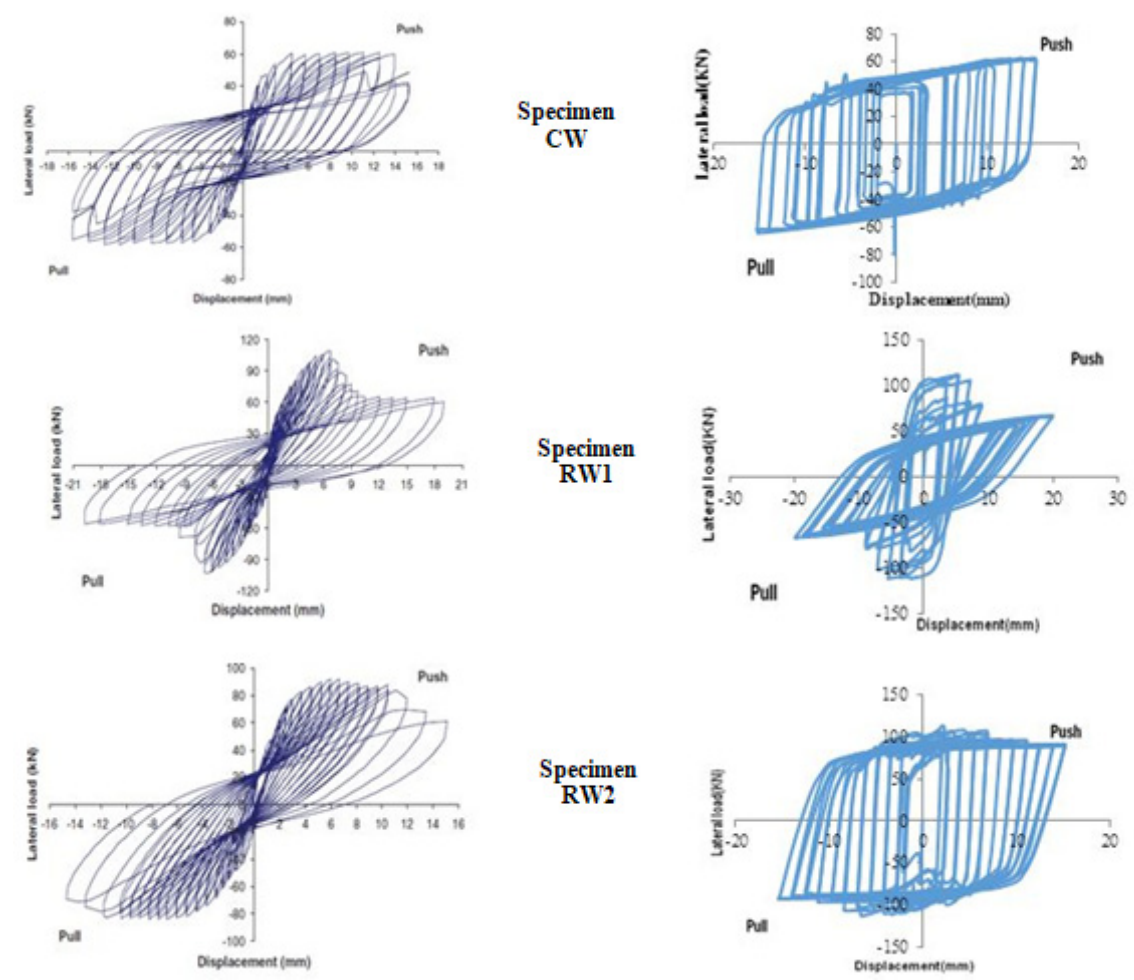

Fig. 4. Force-drift hysteresis curve under cyclic load, Group B, a) experimental b) numerical
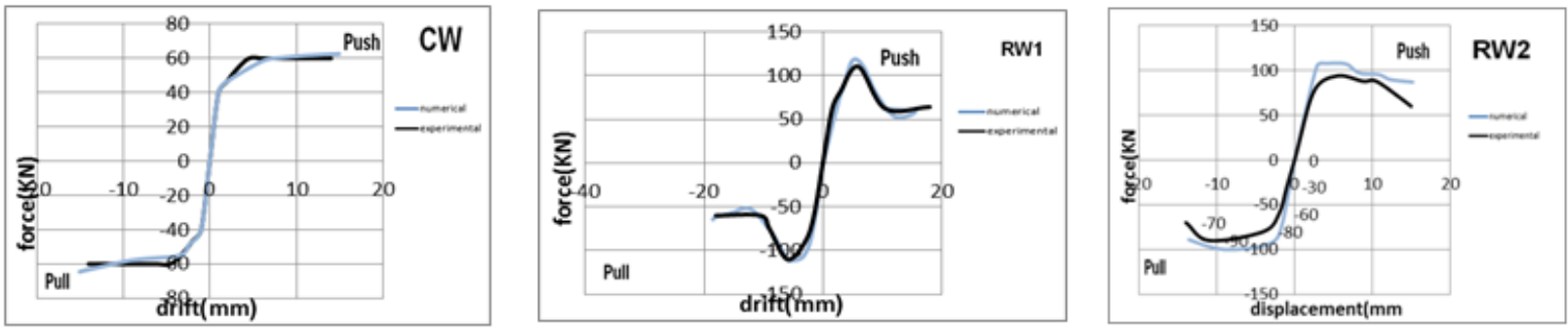

Fig. 5. Push comparison of hysteresis curves of experimental results and numerical analysis for Group B specimens.

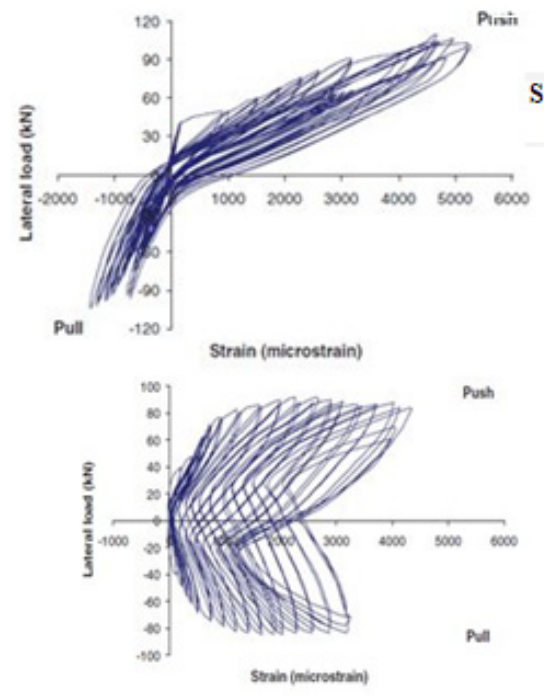

(a)
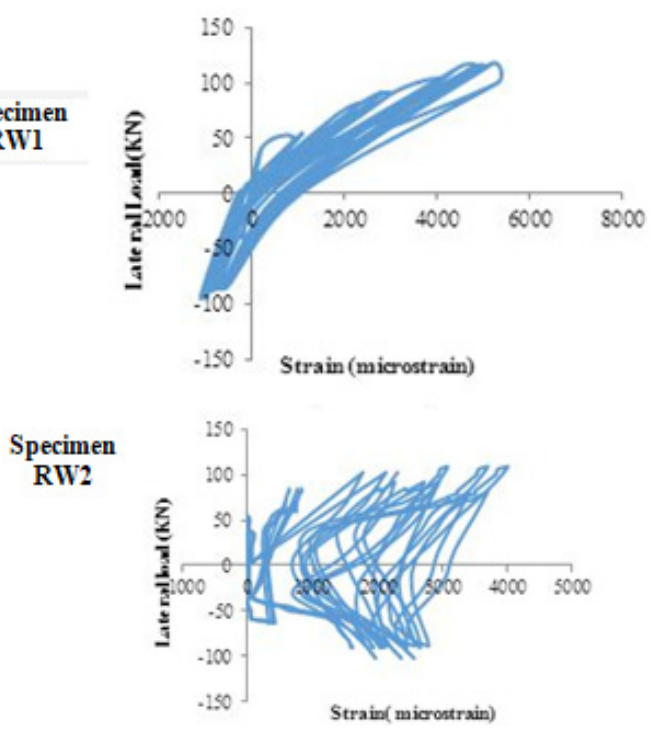

(b)

Fig. 6. Strain-force curve of CFRP in Group B, Specimens RW1 and RW2 a) experimental b) numerical 


\section{Group $C$}

Figure 7 shows force-drift hysteresis curve for Group C specimens under cyclic load [13]. Figure 8 compares the experimental and numerical push of force-drift hysteresis curves. Table $\mathrm{X}$ lists the experimental results and compares them to numerical analysis related to maximum forced obtained in reciprocating cycles. As shown numerical analysis results are consistent with the experimental results.
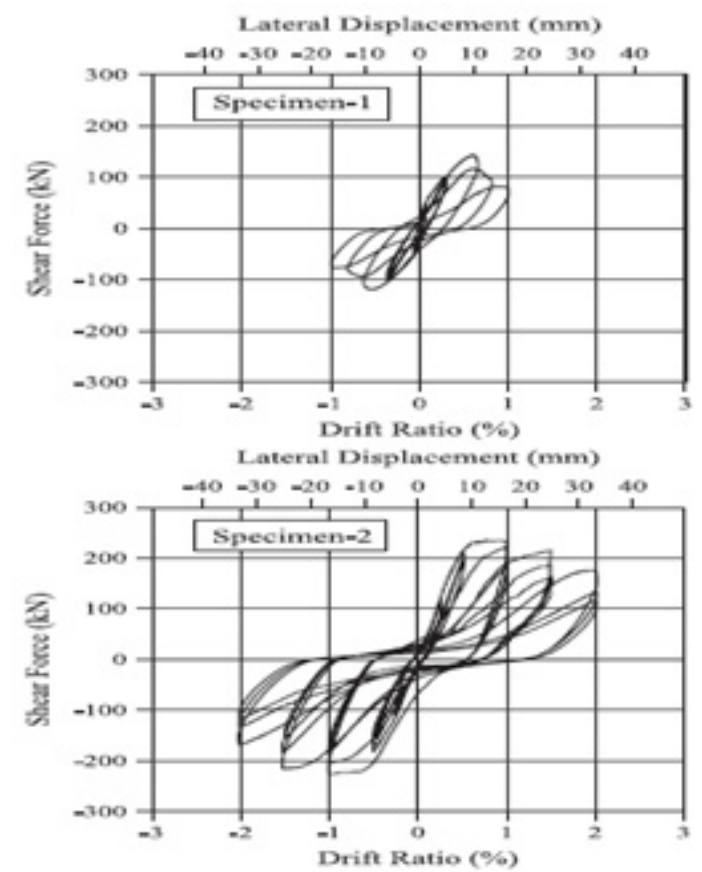

Lateral Displacement (mm)

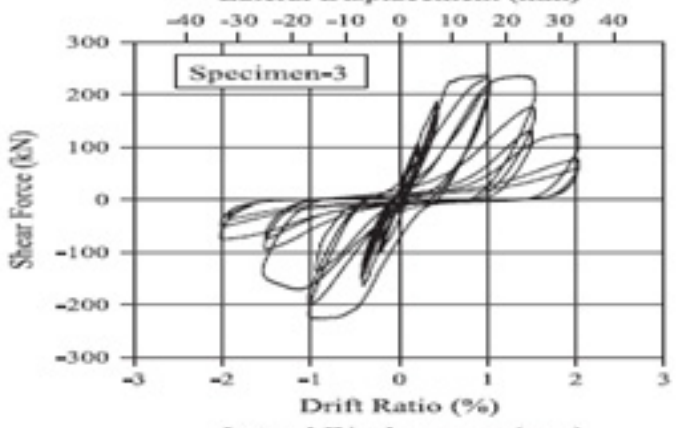

Lateral Displacement (mm)

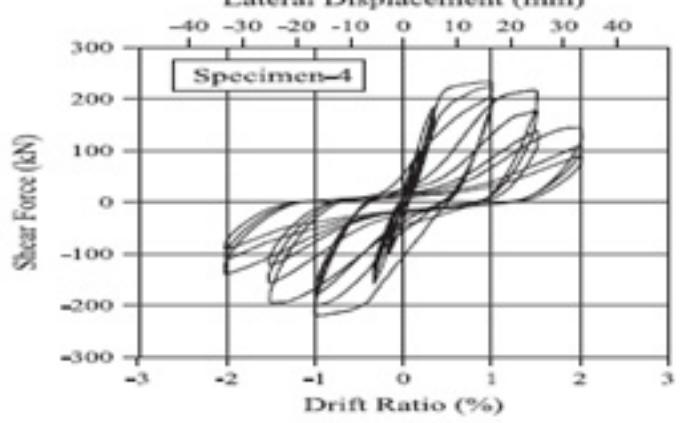

TABLE X. COMPARISON OF MAXIMUM FORCE

\begin{tabular}{|c|c|c|c|c|c|c|}
\hline \multirow{2}{*}{ Specimen } & \multicolumn{2}{|c|}{ Exp } & \multicolumn{2}{c|}{ Num } & \multicolumn{2}{c|}{ Num/ Exp } \\
\cline { 2 - 7 } & $\begin{array}{c}\text { Push } \\
\text { (KN) }\end{array}$ & $\begin{array}{c}\text { Pull } \\
(\text { KN) }\end{array}$ & $\begin{array}{c}\text { Push } \\
\text { (KN) }\end{array}$ & $\begin{array}{c}\text { Pull } \\
(\text { KN) }\end{array}$ & $\begin{array}{c}\text { Push } \\
\text { (KN) }\end{array}$ & $\begin{array}{c}\text { Pull } \\
\text { (KN) }\end{array}$ \\
\hline Specimen1 & 140 & 150 & 131.9 & 150 & 0.94 & 1 \\
\hline Specimen2 & 238 & 245 & 239.15 & 254.07 & 1.004 & 1.04 \\
\hline Specimen3 & 222 & 220 & 219.12 & 225.99 & 0.99 & 1.03 \\
\hline Specimen4 & 225 & 208 & 215.73 & 228.65 & 0.96 & 1.09 \\
\hline
\end{tabular}
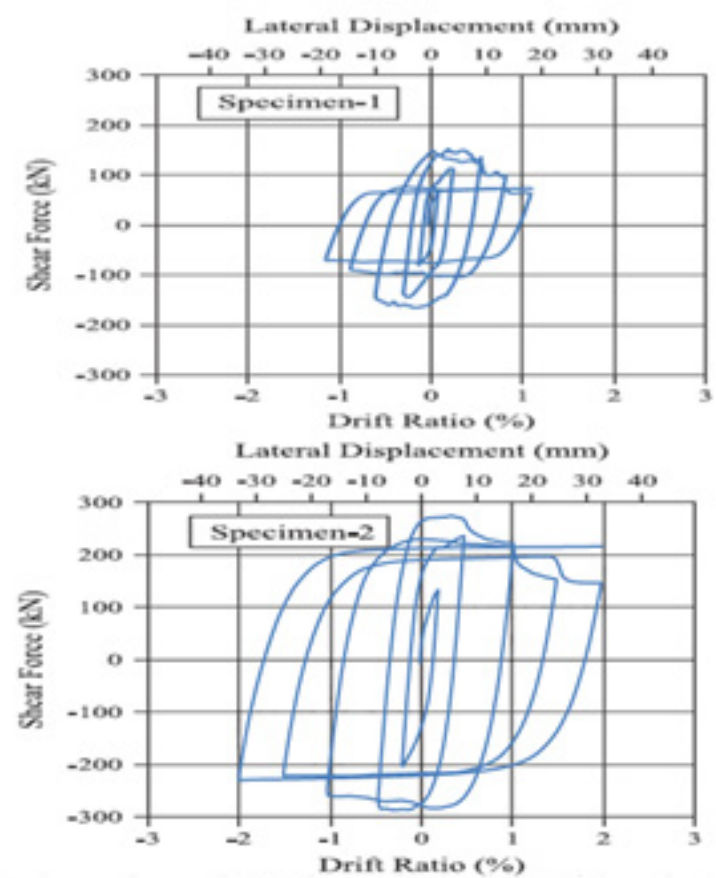

Lateral Displacement $(\mathrm{mm})$
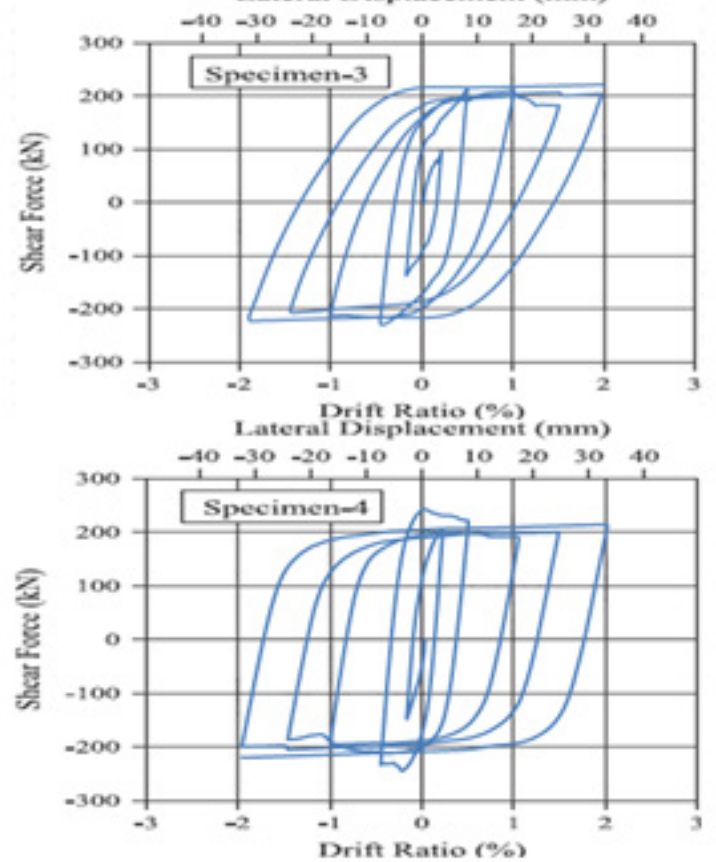

Fig. 7. Force-drift hysteresis curve under cyclic load, Group C-Specimens 1-4 a) experimental b) numerical 

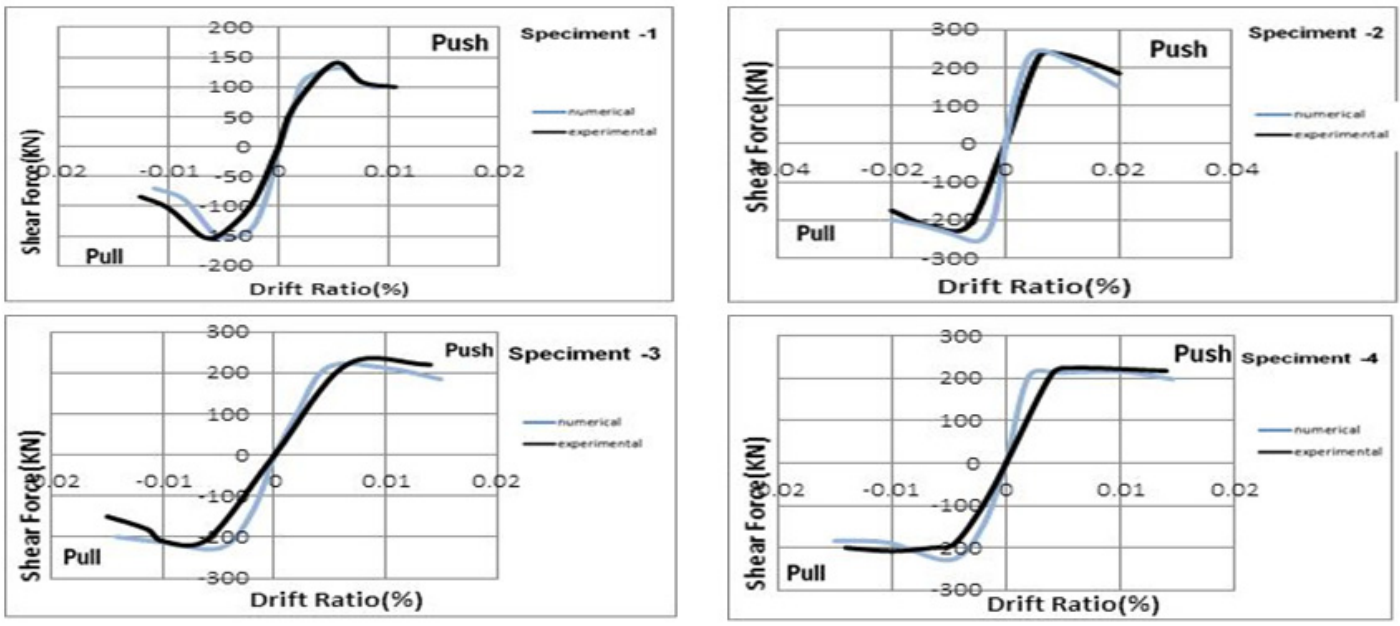

Fig. 8. Push comparison of hysteresis curves of experimental results and numerical analysis (Group C)

\section{CONCLUSION}

Close results of numerical analysis and experiments on specimens before and after FRP reinforcement indicate that numerical modeling can be used as a scientific and inexpensive tool for analyzing the cyclic behavior of unreinforced and FRP reinforced concrete shear walls. Both numerical and experimental results showed that reinforcement of reinforced concrete shear walls, which have shear weakness under seismic loads by FRP coating, is a suitable solution for increasing their resistance. Adjustment of reinforced strips was effective on cyclic behavior of reinforced shear walls and failure mode. To compensate shear weakness of reinforced concrete shear walls, it is better to use horizontal strips along transverse reinforcements on both sides of the wall. To compensate bending weakness of reinforced concrete shear walls, FRP plates are installed vertically along the height of shear wall parallel to longitudinal reinforcements. In general, results show that shear positions of fibers concentrated on edges increase bending and shear strength of the wall. Both numerical and experimental results show that FRP materials increase ultimate strength related to reinforced walls compared to unreinforced ones.

\section{REFERENCES}

[1] A. Kheroddin, H. Naderpour, "Nonlinear Finite Element Analysis of R/C Shear Walls Retrofitted Using Externally Bonded Steel Plate and FRP Sheets", 1st International Structural Specialty Conference, pp. 2326, 2006

[2] S. Soroshnia, H. Najafi, M. Mamaghani, M. Mehrvand, The Most Complete Practical Reference of ABAQUS, 2nd ed., Negarandeh Danesh, 2014

[3] Dassault Systemes, Abaqus Analysis User's Manual, Version 6-10, Dassault Systemes Simulia Corp., 2011

[4] I. M. M. Ahmed, Linear and Nonlinear Flexural Stiffness Models for Concrete Walls in High-Rise Buildings, PhD Thesis, University of British Columbia, 2000

[5] D. Mostofinejad, Reinforced concrete structures, 12th ed, Arkaneh Danesh, 2010

[6] A. Saedi-Darian, H. Bahram Pour, H. Arabzadeh, ABAQUS Software Comprehensive Guide, Angizeh, 2011
[7] J. Lee, G. L. Fenves, "Plastic-Damage Model for Cyclic Loading of Concrete Structures", Journal of Engineering Mechanics, Vol. 124, No. 8, pp. 892-900, 1998

[8] H. T. Hu, F. M. Lin, Y. Y. Jan, "Nonlinear finite element analysis of reinforced concrete beams strengthened by fiber-reinforced plastics", Composite Structure, Vol. 63, No. 3-4, pp. 271-281, 2004

[9] A. A. Tasnimi, "Strength and deformation of mid-rise shear walls under load reversal", Engineering Structures, Vol. 22, No. 4, pp. 311-322, 2000

[10] J. H. Thomsen, J. W. Wallace, "Displacement-Based Design of Slender Reinforced Concrete Structural Walls-Experimental Verification", Journal of Structural Engineering, Vol. 130, No. 4, pp. 618-630, 2004

[11] S. Altin, O. Anil, Y. Kopraman, M. Emin Kara, "Hysteretic behavior of RC shear walls strengthened with CFRP strips", Composites Part B: Engineering, Vol. 44, No. 1, pp. 321-329, 2013

[12] H. El-Sokkary, K. Galal, "Seismic Behavior of RC Shear Walls Strengthened with Fiber-Reinforced Polymer", Journal of Composites for Construction, Vol. 17, No. 5, pp. 603-613, 2013

[13] S. Altin, Y. Kopraman, M. Baran, "Strengthening of RC walls using externally bonding of steel strips", Engineering Structures, Vol. 49 pp. 686-695, 2013 